\title{
Supported Heteropolyanions as Solid Counterions for the Electrostatic Immobilization of Chiral Copper Complexes
}

M. Rosario Torviso, ${ }^{1}$ Mirta N. Blanco, ${ }^{2}$ Carmen V. Cáceres, ${ }^{2}$ José M. Fraile, ${ }^{* 3}$ and José A. Mayoral $*^{3}$

${ }^{1}$ Departamento de Química Orgánica, Facultad de Farmacia y Bioquímica, Universidad de Buenos Aires, Junín 956, 1113 Buenos Aires, Argentina.

${ }^{2}$ Centro de Investigación y Desarrollo en Ciencias Aplicadas "Dr. Jorge Ronco" (CINDECA), Departamento de Química, Facultad de Ciencias Exactas, Universidad Nacional de La Plata, CCT-La Plata, CONICET, Calle 47 N²57, 1900 La Plata, Argentina.

${ }^{3}$ Departamento de Química Orgánica, Instituto de Ciencia de Materiales de Aragón and Instituto Universitario de Catálisis Homogénea, Facultad de Ciencias, Universidad de Zaragoza - C.S.I.C., E-50009 Zaragoza (Spain).

\begin{abstract}
Supported $\left(\mathrm{PW}_{12} \mathrm{O}_{40}{ }^{3-}\right.$ ) is a suitable counterion to immobilize chiral azabis(oxazoline)copper complexes through electrostatic interactions (ion pair formation). Catalytic results are good to excellent in cyclopropanation reactions (up to 97\% ee). Partial leaching during recycling when mono-exchanged species are present, favored by strong coordination of by-products, can be minimized by a proper solvent choice and by optimization of the recycling system, allowing the recovery and reuse of the catalyst at least six times without loss of activity and enantioselectivities in the range of $82-96 \%$ ee for trans cyclopropanes.
\end{abstract}

Keywords: heteropolyacids, enantioselective catalysis, immobilized catalysts 


\section{INTRODUCTION}

The inherent practical advantages of heterogeneous over homogeneous catalysts have boosted the research about immobilization of chiral metal complexes to obtain heterogeneous catalysts for enantioselective processes $[1,2]$. Non-covalent methods represent an interesting alternative to covalent immobilization [3], given that in many cases the same homogeneous complex can be used for immobilization without any chemical modification, and hence the preparation of the supported catalyst is made much easier.

In immobilization methods based on electrostatic interactions, the support acts as a counterion for the chiral complex, forming a support-complex ion pair. It is well known the influence of the counterion on the reaction results in different enantioselective reactions. As an example, the stereochemistry of cyclopropanation is modified due to the pyramidalization of the transition states caused by the coordination of anions with strong coordinating ability [4]. For this reason the search of new solid counterions, to be used as supports for chiral catalysts, is an area of interest but unfortunately very few explored. In most of cases anions with a poor coordinating ability are needed, therefore coming from solids with a high acidity such as nafion-like solids [5]. However nafion itself has an extremely low surface area, whereas composites are expensive and, in general, display a very low functionalization.

In order to broaden the range of applicability of electrostatically immobilized chiral catalysts, it is important to test other solids with superacidic properties as supports. One example are the Keggin type heteropolyacids [6], that can be immobilized into several supports, silica for instance, acting as acid catalysts in several organic reactions [7-10]. The examples about the use of these solids as supports of chiral catalysts are scarce. Pioneering work by Augustine et al [11-13] described the immobilization of Rh-diphosphine complexes on different alumina-supported heteropolyanions and their use in hydrogenation reactions, with improved activity and enantioselectivity [14, 15], mainly upon recycling. Ru-Binap [16] and Rh-prolinamide [17] complexes were also immobilized by the same procedure. This methodology was compared with the direct cation exchange on nafion-like solids, with better activity and stability against leaching [18], in agreement with a strong support-complex interaction. However, the examples in the literature dealing with the immobilization of other types of complexes or the application in enantioselective reactions different from 
hydrogenation are scarce. Only in one case the immobilization of bis(oxazoline)-copper complexes has been described with no particular success [19].

Bis(oxazoline)-metal complexes constitute one family of versatile enantioselective catalysts [20] widely studied in aspects concerning to immobilization $[21,22]$, and specially with non-covalent immobilization methods. In fact bis(oxazoline)-copper complexes immobilized by non-covalent methods have been used as catalysts in cyclopropanation [5,23], Diels-Alder [24], aziridination [25], Mukaiyama aldol reactions [26], and carbene insertions into C-H bonds [27]. Moreover, the support surface may play an important role in the stereochemical course of the enantioselective reactions [28], demonstrated in different examples with copper complexes immobilized by electrostatic interactions [29-31]. The aim of this work is to study the possible use of supported heteropolyanions, in this case phosphotungstate, as carriers for chiral copper complexes.

\section{EXPERIMENTAL}

\subsection{Preparation of ligands}

Azabox ligands (Fig. 1) were prepared by the method described by Reiser and coworkers [32].

$$
\text { Insert Figure } 1
$$

\subsection{Neutralization of the unsupported heteropolyacid}

$\mathrm{H}_{3} \mathrm{PW}_{12} \mathrm{O}_{40} \cdot \mathrm{nH}_{2} \mathrm{O}$ (PW, Fluka) was calcined at $200^{\circ} \mathrm{C}$ for $3 \mathrm{~h}$. Triethylamine $(0.2$ $\mathrm{ml}, 1.2 \mathrm{meq})$ was added to a suspension of calcined PW (1 g, $0.347 \mathrm{mmol})$ in dichloromethane $(5 \mathrm{ml})$, and the mixture was stirred for $24 \mathrm{~h}$ at room temperature $(\mathrm{rt})$. After concentration under vacuum, the solid was filtered off, washed with dichloromethane and dried to obtain the neutralized heteropolyacid PWn.

\subsection{Preparation of the immobilized heteropolyacid}

PW was immobilized on Ralt-Chemie silica (surface area $253 \mathrm{~m}^{2} / \mathrm{g}$, pore volume $1.1 \mathrm{~cm}^{3} / \mathrm{g}$, mean pore diameter $11.3 \mathrm{~nm}$ ) with a particle size $0.15-0.21 \mathrm{~mm}\left(\mathrm{~S}_{\mathrm{R}}\right)$ or a particle size $0.42-0.84 \mathrm{~mm}\left(\mathrm{~S}_{\mathrm{R} 2}\right)$, Grace-Davison silica $\left(\mathrm{S}_{\mathrm{G}}\right.$, surface area $311 \mathrm{~m}^{2} / \mathrm{g}$, pore volume $1.7 \mathrm{~cm}^{3} / \mathrm{g}$, mean pore diameter $5-10 \mathrm{~nm}$ ) or Alfa Aesar alumina (A, surface area $220 \mathrm{~m}^{2} / \mathrm{g}$, pore volume $0.62 \mathrm{~cm}^{3} / \mathrm{g}$, mean pore diameter $7 \mathrm{~nm}$ ). 
In the case of $S_{R}, S_{R 2}$, and $A$, immobilization was carried out by the pore filling impregnation method [33]. In a typical preparation the support (1 g) was immersed into a solution of $\mathrm{PW}(1.1 \mathrm{ml}, 0.19 \mathrm{~g} \mathrm{PW} / \mathrm{ml})$ in $\mathrm{EtOH} / \mathrm{H}_{2} \mathrm{O}=1: 1 \mathrm{v} / \mathrm{v}$, at room temperature for $72 \mathrm{~h}$. After this time, the solid was dried at $\mathrm{rt}$ for $24 \mathrm{~h}$, and calcined at $200^{\circ} \mathrm{C}$ for $3 \mathrm{~h}$. The calcined solid was stirred in dichloromethane $(10 \mathrm{ml})$ for $24 \mathrm{~h}$, separated by filtration and this process was repeated twice. Finally the solid was again calcined at $200^{\circ} \mathrm{C}$ for $3 \mathrm{~h}$.

In the case of $\mathrm{S}_{\mathrm{G}}$, immobilization was carried out by the equilibrium impregnation method [34]. In a typical preparation silica $\mathrm{S}_{\mathrm{G}}(1 \mathrm{~g})$ was immersed into a solution of $\mathrm{PW}(4 \mathrm{ml}, 0.12 \mathrm{~g} \mathrm{PW} / \mathrm{ml})$ in $\mathrm{EtOH} / \mathrm{H}_{2} \mathrm{O}=1: 1 \mathrm{v} / \mathrm{v}$, under constant stirring at room temperature for $72 \mathrm{~h}$. After this time the solid was separated from the solution by centrifugation, dried for $24 \mathrm{~h}$ at room temperature, and calcined at $200^{\circ} \mathrm{C}$ for $3 \mathrm{~h}$. The calcined solid was stirred in dichloromethane $(10 \mathrm{ml})$ for $24 \mathrm{~h}$, separated by filtration and this process was repeated twice. Finally the solid was dried and calcined as before washing.

The immobilized heteropolyacid $\left(\mathrm{PW}-\mathrm{S}_{\mathrm{R}} / \mathrm{S}_{\mathrm{R} 2} / \mathrm{S}_{\mathrm{G}} / \mathrm{A}, 1 \mathrm{~g}\right)$ was neutralized by stirring in a solution of triethylamine $(0.05 \mathrm{ml}, 0.34 \mathrm{meq})$ in dichloromethane $(5 \mathrm{ml})$. Then the solid ( $\mathrm{PWn}-\mathrm{S}_{\mathrm{R}} / \mathrm{S}_{\mathrm{R} 2} / \mathrm{S}_{\mathrm{G}} / \mathrm{A}$ ) was separated by filtration, thoroughly washed with dichloromethane and dried under vacuum.

\subsection{Preparation of the immobilized catalyst}

The chiral ligand $(0.02 \mathrm{mmol})$ and $\mathrm{Cu}(\mathrm{OTf})_{2}(7.3 \mathrm{mg}, 0.02 \mathrm{mmol})$ were dissolved in the minimum amount of anhydrous dichloromethane under an argon atmosphere. The solution was stirred for $15 \mathrm{~min}$ and filtered through a PTFE microfilter and the solvent was removed under an argon flow. The complex was redissolved in nitroethane ( $5 \mathrm{ml}$, pretreated with $\mathrm{Na}_{2} \mathrm{CO}_{3}$ and distilled to eliminate all the acid traces) and the required amount of support (PWn, PWn-S $\left., \mathrm{PWn}-\mathrm{S}_{\mathrm{R} 2}, \mathrm{PWn}-\mathrm{S}_{\mathrm{G}}, \mathrm{PWn}-\mathrm{A}\right)$ was added. The suspension was stirred under argon for $24 \mathrm{~h}$ at $\mathrm{rt}$. The solid was separated by filtration, thoroughly washed with nitroethane and dichloromethane, and dried under vacuum.

\subsection{Characterization of supports and catalysts}

Elemental analysis was performed in a Perkin-Elmer 2400 elemental analyzer. Copper and tungsten analysis was carried out by ICP in a Perkin-Elmer Plasma 40 
emission spectrometer. FT-IR spectra of the solids in $\mathrm{KBr}$ wafers treated at $200^{\circ} \mathrm{C}$ under vacuum $\left(10^{-4}\right.$ torr) were recorded in a Nicolet Avatar 360 FTIR spectrophotometer. ${ }^{31} \mathrm{P}-$ and ${ }^{13} \mathrm{C}-\mathrm{CP}-\mathrm{MAS}-\mathrm{NMR}$ spectra were measured at room temperature on a Bruker Avance III WB400 spectrometer at 161.99 and $100.63 \mathrm{MHz}$ respectively. Solid samples

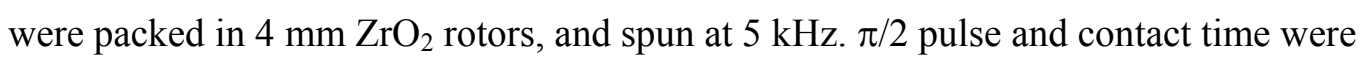
respectively $5 \mu$ s and $3 \mathrm{~ms}$ for ${ }^{31} \mathrm{P}$ and $2.45 \mu$ s and $2 \mathrm{~ms}$ for ${ }^{13} \mathrm{C}$. XPS measurements were carried out on an Axis Ultra DLD (Kratos Tech.) with monochromatized A1Ka source $(1486.6 \mathrm{eV})$ at $15 \mathrm{kV}$ and $10 \mathrm{~mA}$. Samples were evacuated at room temperature.

\subsection{Typical cyclopropanation reaction}

Ethyl diazoacetate $(5 \mathrm{mmol})$ was slowly added $(2 \mathrm{~h})$ with a syringe pump over a stirred solution or suspension formed by styrene ( $5 \mathrm{mmol}), n$-decane $(100 \mathrm{mg}$, internal standard) and catalyst (see Tables 1-3 for amounts) in dichloromethane (4 ml) at rt. The reaction mixture was stirred for $24 \mathrm{~h}$. In some cases styrene $(4 \mathrm{ml})$ instead of dichloromethane was used as solvent. The reaction was monitored by GC. FID from Hewlett-Packard 5890II; cross-linked methyl silicone column: $25 \mathrm{~m} \times 0.2 \mathrm{~mm} \times 0.33$ $\mu \mathrm{m}$; helium as carrier gas, 20 p.s.i.; injector temperature: $230^{\circ} \mathrm{C}$; detector temperature: $250{ }^{\circ} \mathrm{C}$; oven temperature program: $70{ }^{\circ} \mathrm{C}(3 \mathrm{~min}), 15^{\circ} \mathrm{C} \min ^{-1}$ to $200{ }^{\circ} \mathrm{C}(5 \mathrm{~min})$; retention times: ethyl diazoacetate $4.28 \mathrm{~min}$, styrene $5.03 \mathrm{~min}, n$-decane (internal standard) $6.93 \mathrm{~min}$, diethyl fumarate $8.73 \mathrm{~min}$, diethyl maleate $9.04 \mathrm{~min}$, ciscyclopropanes $11.84 \mathrm{~min}$, trans-cyclopropanes $12.35 \mathrm{~min}$. Enantioselectivities were also determined by gas chromatography. FID from Hewlett-Packard 5890II, Cyclodex B column: $30 \mathrm{~m} \times 0.25 \mathrm{~mm} \times 0.25 \mu \mathrm{m}$; helium as carrier gas, 20 p.s.i.; injector temperature: $230{ }^{\circ} \mathrm{C}$; detector temperature: $250{ }^{\circ} \mathrm{C}$; oven temperature program: $125^{\circ} \mathrm{C}$ isotherm; retention times: (1S,2R)-cyclopropane $28.9 \mathrm{~min},(1 R, 2 S)$-cyclopropane 29.8 $\min ,(1 R, 2 R)$-cyclopropane $34.3 \mathrm{~min},(1 S, 2 S)$-cyclopropane $34.9 \mathrm{~min}$.

In the case of heterogeneous catalysts, the solid was recovered by different procedures:

- method A: filtration, washing twice with $5 \mathrm{ml}$ of dichloromethane, drying, and reuse under the same conditions, after drying under vacuum.

- method B: centrifugation, washing twice with $5 \mathrm{ml}$ of with hexane, and solid reuse under the same conditions after drying under vacuum (B1) or without drying (B2). 
- method C: solvent evaporation, suspension in hexane (3 ml), centrifugation, washing twice with $3 \mathrm{ml}$ of hexane, drying, and reuse under the same conditions.

\section{RESULTS AND DISCUSSION}

\subsection{Preparation and characterization of catalysts}

Azabis(oxazolines) are structural analogues of bis(oxazolines) and have shown excellent behaviour as chiral ligands in different asymmetric reactions in homogeneous phase $[35,36]$. Furthermore, they lead to stronger complexes, which is advantageous from the point of view of electrostatic immobilization [37]. Two azabox ligands with different substituents (Aza ${ }^{\mathrm{i}} \mathrm{Pr}, \mathrm{Aza} \mathrm{a}^{\mathrm{t}} \mathrm{Bu}$ ) have been used in this work (Fig. 1).

$\mathrm{H}_{3} \mathrm{PW}_{12} \mathrm{O}_{40}(\mathrm{PW})$ was used for immobilization due to its higher acidity in comparison with related heteropolyacids [9], which should confer to the anion a lower coordinating character. In addition, it has been the most used heteropolyacid to immobilize chiral Rh complexes [11,13]. PW was supported on Ralt-Chemie $\left(\mathrm{S}_{\mathrm{R}}\right)$ silica, as well as Alfa Aesar alumina (A), by using the pore filling impregnation method followed by drying and calcination, in a typical process to obtain supported acid catalysts [33]. In the case of Grace-Davison silica, PW was supported by the equilibrium impregnation method [34]. In this regard this methodology is different from that used to immobilize other chiral complexes [11-19], because in those cases PW was supported by the diffusive impregnation method [38], without separation and calcination of the supported PW. This may be the reason why the silica was not a suitable support in those cases, as a very low linkage between PW and the support takes place. Due to the sensitivity of oxazoline-containing ligands to acid-catalyzed hydrolysis, supported and unsupported PW was neutralized (PWn) by stirring in a solution of triethylamine $\left(\mathrm{Et}_{3} \mathrm{~N}\right)$ in dichloromethane prior to exchange with copper complexes. This step was not necessary in the case of Rh-diphosphine complexes and their analogues [11-18], that were immobilized without separation of the supported PW. Our method is also different from that used by Telalovic and Hanefeld [19], because in that case supported PW was not neutralized, copper was first immobilized and then it was complexed with the bis(oxazoline) ligand.

The supported and unsupported PWn was characterized by chemical analysis (Table 1), FT-IR and CP-MAS-NMR. As can be observed from the IR spectra (Fig. 2) the treatment of $\mathrm{PW}$ with $\mathrm{Et}_{3} \mathrm{~N}$ produces clear changes. Firstly, the characteristic band at 
$982 \mathrm{~cm}^{-1}$, assigned to the asymetric stretching of the $\mathrm{W}=\mathrm{O}_{\mathrm{d}}$ bond of the $\left[\mathrm{PW}_{12} \mathrm{O}_{40}\right]^{3-}$ anion, is shifted to $952 \mathrm{~cm}^{-1}$, and is accompanied by a shoulder at $978 \mathrm{~cm}^{-1}$. Also, in addition to the band at $1080 \mathrm{~cm}^{-1}$ attributed to the assymetric stretching of the $\mathrm{P}-\mathrm{O}_{\mathrm{a}}$ bond of the tungstophosphate anion, two new bands appear at 1100 and $1048 \mathrm{~cm}^{-1}$, which can be assigned to the splitting of such band produced when the lacunary $\left[\mathrm{PW}_{11} \mathrm{O}_{39}\right]^{7-}$ species is present $[39,40]$. So, the observed features are compatible with a partial transformation of the primary structure of PW into new species, as the lacunary anion.

On the other hand, the ${ }^{31}$ P-CP-MAS-NMR spectrum of PW (Fig. 3) showed the presence of a sharp signal at $-15.2 \mathrm{ppm}$ characteristic of $\mathrm{H}_{3} \mathrm{PW}_{12} \mathrm{O}_{40}$. The neutralized PWn showed in addition two broad bands at -12.2 and $-13.4 \mathrm{ppm}$, compatible with the presence of dimeric species, probably formed by aggregation with $\mathrm{Et}_{3} \mathrm{~N}$ and favored in solid state. The band at $-15.2 \mathrm{ppm}$ in the supported PW is wider than in the unsupported one, in agreement with the lower mobility (hindered rotation) of the supported species. Finally, the spectrum of the neutralized supported PW presents an important band at $-10.1 \mathrm{ppm}$ [40], probably due to the presence of the lacunary species detected by IR. The relative intensity of that broad band with respect to that of PW is highly dependent on the hydration level of the sample, indicating the efficiency of the cross polarization by the closer proximity of water molecules, in agreement with the lacunary character of those species. Moreover the ${ }^{13} \mathrm{C}-\mathrm{CP}-\mathrm{MAS}-\mathrm{NMR}$ spectrum shows the expected signals at 48.2 and $9.2 \mathrm{ppm}$, corresponding to the triethylammonium cation. The $\mathrm{W}$ content $(64.5 \%)$ is slightly lower than the theoretical value of the expected anhydrous species $\left(\mathrm{Et}_{3} \mathrm{~N}\right)_{3} \mathrm{PW}_{12} \mathrm{O}_{40}(69.3 \%)$, and it may be due to partial hydration and the formation of the spectroscopically detected lacunary species.

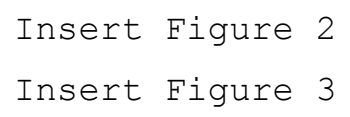

Cation exchange was carried out in nitroethane in order to prevent leaching of PW in methanol, which is the most commonly used solvent with other supports [41]. The required amount of support (PWn, $\left.\mathrm{PWn}-\mathrm{S}_{\mathrm{R}}, \mathrm{PWn}-\mathrm{S}_{\mathrm{G}}, \mathrm{PWn}-\mathrm{A}\right)$ was stirred with a solution of the complex in nitroethane under argon for $24 \mathrm{~h}$ at $\mathrm{rt}$. The solid was separated by filtration, thoroughly washed with nitroethane, and dried under vacuum.

The catalysts were analyzed (Table 1 ) to determine the amount of copper per PW unit, and to compare it with the maximum theoretical cation exchange capacity 
$(\mathrm{Cu} / \mathrm{PW}$ molar ratio $=1.5$, or $\mathrm{Cu} / \mathrm{W}$ molar ratio $=0.125)$. In the case of unsupported $\mathrm{PW}$, the use of an excess of complex during the exchange process leads to a maximum content of $0.186 \mathrm{Cu} / \mathrm{W}$ (entry 3 ), that seems to be the limit for this system given that it is not exceeded by the use of an initial larger copper excess. The existence of an equilibrium is shown by the lower content, $\mathrm{Cu} / \mathrm{W}$ molar ratio $=0.07$ (entry 2), obtained when the theoretical stoichiometric amount of complex is used in the exchange process. In any case it can be seen that the $\mathrm{Cu} / \mathrm{W}$ molar ratio can go beyond the theoretical value necessary to compensate the negative charge of the intact heteropolyanion. An excess of complex was used in the exchange process with supported PW. Values of $\mathrm{Cu} / \mathrm{W}$ molar ratio ranging 0.182-0.342 can be obtained under such conditions (entries 5, 7, 8, 11), whereas the theoretical $\mathrm{Cu} / \mathrm{W}$ molar ratio can be obtained when the initial amount of complex is close to this value (entry 9). Again in most cases the charge corresponding to the amount of immobilized complex exceeds the theoretical exchange capacity of the solid. This may be due to the presence of mono-exchanged species (Fig. 4). The presence of sulphur was detected by XPS in all the samples with an excess of complex, in agreement with the exchange of only one of the triflates of the initial complex. On the contrary, sulphur was not observable in the samples with $\mathrm{Cu} / \mathrm{W}$ values below the theoretical value. However, the mono-exchanged species would explain $\mathrm{Cu} / \mathrm{W}$ values up to 0.25 ( $1 \mathrm{Cu}$ per charge of $\mathrm{PW})$. Higher values must be due to the presence of lacunary heteropolyanion species with higher charge, as shown by the spectroscopic techniques, and/or a contribution of complex adsorption on silica surface. In fact $S_{R}$ support is able to adsorb $0.17 \mathrm{mmol}$ of complex/g (entry 6) and it cannot be discarded the presence of a small amount of complex directly adsorbed on the bare silica or alumina surfaces in all the solids.

Insert Table 1

As above-mentioned, the presence of sulphur coming from triflate was detected by XPS. Values of S/Cu molar ratio ranging between 0.8 and 1.1 were obtained for all the solids exceeding the theoretical $\mathrm{Cu} / \mathrm{W}$ molar ratio. On the contrary sulphur was not detected in $\mathrm{Aza}{ }^{\mathrm{i}} \mathrm{Pr}-\mathrm{Cu}-\mathrm{PWn}$ and $\mathrm{Aza}{ }^{\mathrm{t}} \mathrm{Bu}-\mathrm{Cu}-\mathrm{PWn}-\mathrm{A}$, the two catalysts with $\mathrm{Cu} / \mathrm{W}$ ratio far below the theoretical amount. These results points to the existence of monoexchanged species, as proposed in Fig. 4.

The intact structure of the copper complexes was also confirmed by IR spectroscopy (Fig. 5). The presence of all the bands in the skeletal range of the 
spectrum, mainly the imine bands at 1652 and $1678 \mathrm{~cm}^{-1}$, and the difference from the spectrum of the free ligand $\left(1636 \mathrm{~cm}^{-1}\right)$, are in agreement with the presence of the ligand forming a copper complex.

$$
\text { Insert Figure } 5
$$

Regarding the structure of the supported heteropolyanion, the spectrum is significantly modified after exchange of the copper complex (Fig. 6). The intensity of the band at $978 \mathrm{~cm}^{-1}$ increases, leading to different relative intensities with respect to the band at $952 \mathrm{~cm}^{-1}$, that depends on the loading of complex. This result seems to indicate the coexistence of two types of $\mathrm{W}=\mathrm{O}$ sites, one compatible with the lacunary species $\left(952 \mathrm{~cm}^{-1}\right)$ and the other one $\left(978 \mathrm{~cm}^{-1}\right)$ compatible with the intact Keggin heteropolyanion. The increase of this signal after complex exchange seems to indicate that copper occupies the $\mathrm{W}$ vacant in the lacunary species [42].

$$
\text { Insert Figure } 6
$$

\subsection{Cyclopropanation reactions}

The catalysts were tested in the benchmark reaction between styrene and ethyl diazoacetate (Fig. 7) and the results, compared with those obtained with other homogeneous and immobilized catalysts, are gathered in Table 2.

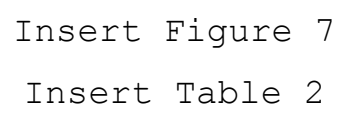

In a first set of experiments the immobilized catalysts were tested in dichloromethane, recovered by filtration and washing with the same solvent (method A), and reused under the same conditions. The results are presented in Table 2. All the reactions, with the freshly prepared catalysts, showed a total conversion of ethyl diazoacetate to either cyclopropanes or dimerization products (diethyl fumarate and maleate). Hence the yield reported is in fact the chemoselectivity to cyclopropanation reaction. The heterogeneous character of the catalysts was tested by adding ethyl diazoacetate to the filtrate. In all cases the yield increase was lower than $2 \%$, showing that the contribution of the homogeneous reaction is negligible. The only exception was the catalyst prepared by direct adsorption on silica ( $\mathrm{Aza}{ }^{\mathrm{t}} \mathrm{Bu}-\mathrm{Cu}-\mathrm{S}_{\mathrm{R}}$, entry 11$)$, in which the contribution of the homogeneous reaction was significant. 
A first conclusion is the suitable nature of the PW anion to act as counterion for azabox-Cu complexes. The results in "quasi-homogeneous" phase show that enantioselectivity similar to that obtained with triflate can be reached with Aza ${ }^{\mathrm{i}} \operatorname{Pr}$ (entry 3) or $\mathrm{Aza}{ }^{t} \mathrm{Bu}$ ligands (entry 10), whereas the final yield increases with higher catalyst amount, due to a higher chemoselectivity. The immobilization of PW is highly positive in the case of Aza $\mathrm{Pr}-\mathrm{Cu}$ (entry 4), leading to better results than the complex immobilized on laponite (entry 2 ) and even better enantioselectivity than that originally reported in the literature (entry 1). This is also the case of $\mathrm{Aza}{ }^{\mathrm{t}} \mathrm{Bu}-\mathrm{Cu}$ (entry 13), when compared with the catalysts immobilized on laponite (entry 6) or a nafion-silica support (entry 8).

Several parameters have been studied with $\mathrm{Aza}{ }^{t} \mathrm{Bu}-\mathrm{Cu}$. The morphology of the silica support has some effect on the catalytic activity, although the selectivities are always at the same level. Ralt-Chemie silica (entry 13) performs better than GraceDavison (entry 18) as support. The larger pore size, and then a better accessibility to the catalytic sites, may account for this behavior. An increase in particle size, with a consequent reduction in the external surface, is detrimental for the catalytic activity (entry 16 vs 13), probably due to intraparticle diffusion limitations. Finally the performance of alumina (entry 24) is the lowest among the tested supports, probably due to the strong interaction of PWn with alumina, and to the tungstophosphate anion is transformed into another species [40].

Recovery and reuse were tested in most of the catalysts. In all cases a significant drop in activity and enantioselectivity is observed from the second run, or the third at most, when a larger amount of catalyst is used (entry 20). This drop in activity has as a result the lack of total conversion of ethyl diazoacetate observed with the fresh catalysts. This effect is not due to leaching of active copper, as mentioned above, but probably to a deactivation of the complex due to adsorption of by-products obtained from the competitive dimerization and/or polymerization of ethyl diazoacetate to diethyl fumarate, diethyl maleate and poly(ethyl 2-ylidene acetate) [44]. These products are easily detectable in the used catalysts by IR due to the presence of the prominent $\mathrm{C}=\mathrm{O}$ band and they contribute to the increase in $\mathrm{C}$ content of the used catalysts. This increase makes it difficult to directly compare the copper content in the used and the fresh catalysts. As the W/Si ratio is kept constant, the leaching of the whole PW species from the support can be discarded, in agreement with the low solubility of PW in low polarity solvents, such as the reaction medium [34]. However, the drop in the $\mathrm{Cu} / \mathrm{W}$ ratio in the 
catalysts used once, in agreement with a copper leaching in the range of $15-40 \%$, and the absence of sulphur in them, point to a loss of mono-exchanged species in the $\mathrm{Cu}$ (II)$\mathrm{Cu}(\mathrm{I})$ reduction process previous to the catalytic reaction (Fig. 4). In some experiments $\mathrm{Aza}{ }^{\mathrm{t}} \mathrm{Bu}-\mathrm{Cu}_{0.5}-\mathrm{PWn}-\mathrm{S}_{\mathrm{R}}$ was treated with ethyl diazoacetate in dichloromethane to reduce $\mathrm{Cu}(\mathrm{II})$, and the solid was filtered. The activity of the solution gave only $2 \%$ yield with trans/cis $=80: 20$ and lower enantioselectivity (77\% e.e. trans), whereas the solid preserved more than $95 \%$ of the activity observed in a normal reaction, in spite of the loss of copper, demonstrating the absence of significant leaching of active species. After the first reuse, the $\mathrm{Cu} / \mathrm{W}$ ratio is kept stable and further deactivation is due to poisoning. This effect has been observed in several cases, and the copper loss is higher when the $\mathrm{Cu} / \mathrm{W}$ ratio of the catalyst is higher, in agreement with the hypothesis of monoexchanged species (Fig. 4). On the other hand this copper loss is not observed with catalysts having a $\mathrm{Cu} / \mathrm{W}$ ratio below the maximum theoretical cation exchange capacity, in which the presence of sulphur is not detected.

In a second set of experiments, the most promising catalysts were tested in the same reaction but with a large excess of styrene, in the absence of any additional solvent. The comparison with the results in dichloromethane is shown in Table 3. As can be observed, the results are much better in styrene, mainly regarding reuse. Now the solid with larger particle size $\left(\mathrm{S}_{\mathrm{R} 2}\right)$ showed a better performance, with similar yield and selectivities in four consecutive runs. The recoverability of the catalyst is much better in styrene, probably due to the higher chemoselectivity of the reaction, mainly in the case of $\mathrm{S}_{\mathrm{R} 2}$ support. This recoverability drastically increases the productivity of the catalyst. In fact using the homogeneous complex $85 \mathrm{~mol}$ of cyclopropanes per mol of $\mathrm{Cu}$ are obtained, with $93 \%$ e.e. (trans), whereas the heterogeneous catalyst is able to reach 406 mol of cyclopropanes per mol of $\mathrm{Cu}$, with a cumulative $91.7 \%$ e.e. (trans). An additional detrimental factor for recovery is the attrition of the catalyst particles, leading to a mass loss during the filtration, which reduces the effective amount of catalyst in the consecutive runs, with the consequent negative effect on the catalytic activity. In view of that, a study of different recovery processes was performed.

$$
\text { Insert Table } 3
$$

Trying to prevent the mass loss by filtration, catalyst and solution were separated by centrifugation, and the catalyst was washed with hexane instead of dichloromethane (method B). As can be seen in Table 4, this method is especially suitable for reactions 
carried out in styrene. Three consecutive runs were tried with Aza ${ }^{\mathrm{i}} \mathrm{Pr}-\mathrm{Cu}-\mathrm{PWn}-\mathrm{S}_{\mathrm{R}}$, even with very low amount of catalyst, whereas up to six consecutive runs were tested with $\mathrm{Aza}{ }^{\mathrm{t}} \mathrm{Bu}-\mathrm{Cu}_{0.5}-\mathrm{PWn}-\mathrm{S}_{\mathrm{R}}$ and higher amount of catalyst. In view of the detrimental effect of dichloromethane, it was eliminated by evaporation before the centrifugation in the presence of hexane (method $\mathrm{C})$. With this method it is also possible to recover the unsupported azabox-Cu-PWn catalysts, although with the limitations in either activity or enantioselectivity described above. This method also allows the recovery of Aza ${ }^{\mathrm{i}} \mathrm{Pr}-$ $\mathrm{Cu}-\mathrm{PWn}-\mathrm{S}_{\mathrm{R}}$ without any drop in enantioselectivity for four runs, although with a drop in activity after the first run. The detrimental effect of dichloromethane in the separation process was again demonstrated by the deactivation in the fifth run when method B2 (direct centrifugation) was applied instead of method C (evaporation prior centrifugation).

Insert Table 4

The use of supported heteropolyacids as supports for chiral catalysts requires the combination of a suitable preparation methods of the chiral heterogeneous catalyst (support, PW impregnation method, chiral ligand, cation exchange method) with an optimized reaction-recovery procedure (solvent, separation method, washing) to obtain good results in catalytic activity, enantioselectivity and recoverability in the cyclopropanation of ethyl diazoacetate and styrene. These results open the way to the development of new chiral heterogeneous catalysts of wide applicability in enantioselective synthesis.

\section{Conclusions}

Tungstophosphate $\left(\mathrm{PW}_{12} \mathrm{O}_{40}{ }^{3-}\right)$ is a suitable counterion for azabis(oxazoline)copper complexes used as catalysts of cyclopropanation reactions. The performance of this counterion increases when it is immobilized on supports with large surface area, such as silica and alumina. The nature and morphology of the support have an influence on the catalytic results, with silica Ralt-Chemie being the most efficient. The method of separation and recovery of the catalyst is also crucial to obtain good recycling behavior. Centrifugation and exclusion of dichloromethane in the separation process are key points allowing up to six consecutive runs with stable activity, reaching productivities higher than $400 \mathrm{~mol} / \mathrm{mol} \mathrm{Cu}$, and enantioselectivity in the range of $82-96 \%$ ee for the trans cyclopropane. 


\section{Acknowledgement}

This work was made possible thanks to the generous financial support of the Spanish Ministerio de Ciencia e Innovación (projects CTQ2008-05138 and Consolider Ingenio 2010 CSD2006-0003), the the Diputación General de Aragón (E11 Group co-financed by the European Regional Development Funds), and the Agencia Española de Cooperación Internacional (project A/5392/06).

\section{References}

[1] D. E. De Vos, I. F. J. Vankelecom, P. A. Jacobs (Eds.), Chiral Catalysts Immobilization and Recycling, Wiley-VCH, Weinheim, 2000.

[2] M. Heitbaum, F. Glorius, I. Escher, Angew. Chem. Int. Ed. 45 (2006) 4732.

[3] J. M. Fraile, J. I. García, J. A. Mayoral, Chem. Rev. 109 (2009) 360.

[4] J. M. Fraile, J. I. García, M. J. Gil, V. Martínez-Merino, J. A. Mayoral, L. Salvatella, Chem. Eur. J. 10 (2004) 758.

[5] J. M. Fraile, J. I. García, C. I. Herrerías, J. A. Mayoral, M. Harmer, J. Catal. 221 (2004) 532.

[6] J. F. Keggin, Proc. Royal Soc. London, A 144 (1934) 75.

[7] T. Okuhara, Chem. Rev. 102 (2002) 3641.

[8] N. Mizuno, M. Misono, Chem Rev. 98 (1998) 199.

[9] I. V. Kozhevnikov, Chem. Rev. 98 (1998) 171.

[10] M. N. Timofeeva, Appl. Catal. A 256 (2003) 19.

[11] R. Augustine, S. Tanielyan, S. Anderson, H. Yang, Chem. Commun. 1999, 1257.

[12] R. L. Augustine, S. K. Tanielyan, N. Mahata, Y. Gao, A. Zsigmond, H. Yang, Appl. Catal. A 256 (2003) 69.

[13] R. L. Augustine, P. Goel, N. Mahata, C. Reyes, S. K. Tanielyan, J. Mol. Catal. A $216(2004) 189$.

[14] Á. Zsigmond, I. Balatoni, F. Notheisz, C. Hegedüs, J. Bakos, Catal. Lett. 101 (2005) 195.

[15] Á. Zsigmond, S. Undrala, F. Notheisz, Á. Szöllösy, J. Bakos, Appl. Catal., A 303 (2006) 29.

[16] J. A. M. Brandts, P. H. Berben, Org. Proc. Res. Develop. 7 (2003) 393.

[17] Á. Zsigmond, K. Bogár, F. Notheisz, J. Catal. 213 (2003) 103. 
[18] C. Simons, U. Hanefeld, I. W. C. E. Arends, T. Maschmeyer, R. A. Sheldon, J. Catal. 239 (2006) 212.

[19] S. Telalovic, U. Hanefeld, Appl. Catal. A 372 (2010) 217.

[20] G. Desimoni, G. Faita, K. A. Jørgensen, Chem. Rev. 106 (2006) 3561.

[21] J. M. Fraile, J. I. García, J. A. Mayoral, Coord. Chem. Rev. 252 (2008) 624.

[22] J. M. Fraile, J. I. García, C. I. Herrerías, J. A. Mayoral, E. Pires, L. Salvatella, Catal. Today 140 (2009) 44.

[23] M. J. Fernández, J. M. Fraile, J. I. García, J. A. Mayoral, M. I. Burguete, E. García-Verdugo, S. V. Luis, M. A. Harmer, Topics Catal. 13 (2000) 303.

[24] H. Wang, X. Liu, H. Xia, P. Liu, J. Gao, P. Ying, J. Xiao, C. Li, Tetrahedron 62 (2006) 1025.

[25] C. Langham, P. Piaggio, D. Bethell, D. F. Lee, P. McMorn, P. C. Bulman-Page, D. J. Willock, C. Sly, F. E. Hancock, F. King, G. J. Hutchings, Chem. Commun. (1998) 1601.

[26] J. M. Fraile, I. Pérez, J. A. Mayoral, O. Reiser, Adv. Synth. Catal. 348 (2006) 1680.

[27] J. M. Fraile, J. I. García, J. A. Mayoral, M. Roldán, Org. Lett. 9 (2007) 731.

[28] J. M. Fraile, J. I. García, C. I. Herrerías, J. A. Mayoral, E. Pires, Chem. Soc. Rev. 38 (2009) 695.

[29] J. I. García, B. López-Sánchez, J. A. Mayoral, E. Pires, I. Villalba, J. Catal. 258 (2008) 378.

[30] J. M. Fraile, J. I. García, G. Jiménez-Osés, J. A. Mayoral, M. Roldán, Organometallics 27 (2008) 2246.

[31] M. J. Fabra, J. M. Fraile, C. I. Herrerías, F. J. Lahoz, J. A. Mayoral, I. Pérez, Chem. Commun. (2008) 5402.

[32] H. Werner, R. Vicha, A. Gissibl, O. Reiser, J. Org. Chem. 68 (2003) 10166.

[33] M. R. Torviso, E. N. Alesso, G. Y. Moltrasio, P. G. Vázquez, L. R. Pizzio, C. V. Cáceres, M. N. Blanco, Appl. Catal. A 301 (2006) 25.

[34] P. Váquez, L. Pizzio, C. Cáeres, M. Blanco, H. Thomas, E. Alesso, L. Finkielsztein, B. Lantaño, G. Moltrasio, J. Aguirre, J. Mol. Catal. A 161 (2000) 223.

[35] A. Gissibl, M. G. Finn, O. Reiser, Org. Lett. 7 (2005) 2325.

[36] C. Geiger, P. Kreitmeier, O. Reiser, Adv. Synth. Catal. 347 (2005) 249. 
[37] J. M. Fraile, J. I. García, C. I. Herrerías, J. A. Mayoral, O. Reiser, A. Socuellamos, H. Werner, Chem. Eur. J. 10 (2004) 2997.

[38] A. V. Nelmark, L. I. Kheifez, V. B. Fenelonov, Ind. Eng. Chem. Prod. Res. Dev. $20(1981) 439$.

[39] L. Pizzio, G. Romanelli, P. Vázquez, J. Autino, M. Blanco, C. Cáceres, Appl. Catal. A 308 (2006) 153.

[40] L. R. Pizzio, C. V. Cáceres, M. N. Blanco, Appl. Catal. A 167 (1998) 283.

[41] J. M. Fraile, J. I. García, J. A. Mayoral, T. Tarnai, Tetrahedron: Asymmetry 9 (1998) 3997.

[42] C. Rocchiccioli-Deltcheff, M. Fournier, J. Chem. Soc. Faraday Trans. 87 (1991) 3913.

[43] M. Glos, O. Reiser, Org. Lett. 2 (2000) 2045.

[44] A. F. Noels, Angew. Chem. Int. Ed. 46 (2007) 1208. 
Table 1. Analysis of the catalysts.

\begin{tabular}{|c|c|c|c|c|c|}
\hline Entry & Catalyst & $\begin{array}{l}\text { Initial Cu } \\
\text { amount }^{\mathrm{a}} \\
(\mathrm{mmol} / \mathrm{g})\end{array}$ & $\begin{array}{c}\mathrm{W} \\
(\mathrm{mmol} / \mathrm{g})\end{array}$ & $\begin{array}{c}\mathrm{Cu} \\
(\mathrm{mmol} / \mathrm{g})\end{array}$ & $\begin{array}{c}\text { Molar ratio } \\
\mathrm{Cu} / \mathrm{W}\end{array}$ \\
\hline 1 & PWn & - & 3.51 & - & - \\
\hline 2 & $\mathrm{Aza}^{\mathrm{i}} \mathrm{Pr}-\mathrm{Cu}-\mathrm{PWn}$ & 0.50 & 3.28 & 0.23 & 0.070 \\
\hline 3 & $\mathrm{Aza}^{t} \mathrm{Bu}-\mathrm{Cu}-\mathrm{PWn}$ & 0.82 & 3.22 & 0.60 & 0.186 \\
\hline 4 & $\mathrm{PWn}-\mathrm{S}_{\mathrm{R}}$ & - & 1.13 & - & - \\
\hline 5 & $\mathrm{Aza}^{\mathrm{i}} \mathrm{Pr}-\mathrm{Cu}-\mathrm{PWn}-\mathrm{S}_{\mathrm{R}}$ & 0.47 & 0.99 & 0.18 & 0.182 \\
\hline 6 & $\mathrm{Aza}{ }^{t} \mathrm{Bu}-\mathrm{Cu}-\mathrm{S}_{\mathrm{R}}{ }^{\mathrm{b}}$ & 0.50 & - & 0.17 & - \\
\hline 7 & $\mathrm{Aza}^{\mathrm{t}} \mathrm{Bu}-\mathrm{Cu}_{0.5}-\mathrm{PWn}-\mathrm{S}_{\mathrm{R}}$ & 0.50 & 0.96 & 0.25 & 0.260 \\
\hline 8 & $\mathrm{Aza}^{\mathrm{t}} \mathrm{Bu}-\mathrm{Cu}-\mathrm{PWn}-\mathrm{S}_{\mathrm{R} 2}$ & 0.50 & 0.79 & 0.27 & 0.342 \\
\hline 9 & $\mathrm{Aza}{ }^{t} \mathrm{Bu}-\mathrm{Cu}_{0.2}-\mathrm{PWn}-\mathrm{S}_{\mathrm{R}}$ & 0.20 & 1.01 & 0.12 & 0.119 \\
\hline 10 & $\mathrm{PWn}-\mathrm{S}_{\mathrm{G}}$ & - & 1.26 & - & - \\
\hline 11 & $\mathrm{Aza}{ }^{t} \mathrm{Bu}-\mathrm{Cu}-\mathrm{PWn}-\mathrm{S}_{\mathrm{G}}$ & 0.50 & 1.21 & 0.32 & 0.264 \\
\hline 12 & PWn-A & - & 1.23 & - & - \\
\hline 13 & $\mathrm{Aza}{ }^{t} \mathrm{Bu}-\mathrm{Cu}-\mathrm{PWn}-\mathrm{A}$ & 0.50 & 1.19 & 0.08 & 0.067 \\
\hline
\end{tabular}

${ }^{\mathrm{a}}$ Amount of copper used in the preparation of the immobilized catalysts. ${ }^{\mathrm{b}}$ Complex adsorbed on silica without PW. 
Table 2. Results obtained in the cyclopropanation reaction between styrene and ethyl diazoacetate in dichloromethane catalyzed by Azabox-Cu(II) complexes. ${ }^{\text {a }}$

\begin{tabular}{|c|c|c|c|c|c|c|c|}
\hline Entry & Catalyst & $\%$ cat & run & $\begin{array}{l}\% \\
\text { yield }^{b}\end{array}$ & trans $/$ cis $^{\mathrm{b}}$ & $\begin{array}{l}\% \text { ee } \\
\text { trans }\end{array}$ & $\begin{array}{l}\% \text { ee } \\
\text { cis }^{\mathrm{b}}\end{array}$ \\
\hline 1 & $\mathrm{Aza}{ }^{\mathrm{i}} \operatorname{Pr}-\mathrm{Cu}(\mathrm{OTf})_{2}{ }^{\mathrm{c}}$ & 1 & 1 & 78 & $66: 34$ & 66 & 44 \\
\hline 2 & Aza $^{\mathrm{i}} \operatorname{Pr}-\mathrm{Cu}-$ Laponite $^{\mathrm{d}}$ & 0.45 & 1 & 39 & $62: 38$ & 54 & 43 \\
\hline 3 & $\mathrm{Aza}^{\mathrm{i}} \mathrm{Pr}-\mathrm{Cu}-\mathrm{PWn}$ & 0.22 & 1 & 17 & $73: 27$ & 62 & 52 \\
\hline 4 & Aza ${ }^{i} \mathrm{Pr}-\mathrm{Cu}-\mathrm{PWn}-\mathrm{S}_{\mathrm{R}}$ & 0.22 & 1 & 47 & $68: 32$ & 70 & 54 \\
\hline 5 & $\mathrm{Aza}{ }^{t} \mathrm{Bu}-\mathrm{Cu}(\mathrm{OTf})_{2}{ }^{\mathrm{c}}$ & 1 & 1 & 82 & $73: 27$ & 92 & 84 \\
\hline 6 & $\mathrm{Aza}^{\mathrm{t}} \mathrm{Bu}-\mathrm{Cu}-$ Laponite ${ }^{\mathrm{d}}$ & 0.45 & 1 & 46 & $71: 29$ & 83 & 76 \\
\hline 7 & & & 2 & 45 & $71: 29$ & 81 & 74 \\
\hline 8 & $\mathrm{Aza}{ }^{t} \mathrm{Bu}-\mathrm{Cu}-\mathrm{Nafion} / \mathrm{SiO}_{2}{ }^{\mathrm{d}}$ & 0.9 & 1 & 30 & $68: 32$ & 88 & 81 \\
\hline 9 & & & 2 & 21 & $66: 34$ & 84 & 77 \\
\hline 10 & Aza ${ }^{t} B u-C u-P W n$ & 0.7 & 1 & 50 & $66: 34$ & 75 & 55 \\
\hline 11 & $\mathrm{Aza}^{\mathrm{t}} \mathrm{Bu}-\mathrm{Cu}-\mathrm{S}_{\mathrm{R}}$ & 0.26 & 1 & 57 & $73: 27$ & 82 & 83 \\
\hline 12 & & & 2 & 6 & $62: 38$ & 45 & 41 \\
\hline 13 & $\mathrm{Aza}^{\mathrm{t}} \mathrm{Bu}-\mathrm{Cu}_{0.5}-\mathrm{PWn}-\mathrm{S}_{\mathrm{R}}$ & 0.5 & 1 & 55 & $73: 27$ & 96 & 85 \\
\hline 14 & & & 2 & 20 & $70: 30$ & 88 & 72 \\
\hline 15 & & & 3 & 3 & $70: 30$ & 62 & 39 \\
\hline 16 & $\mathrm{Aza}{ }^{t} \mathrm{Bu}-\mathrm{Cu}-\mathrm{PWn}-\mathrm{S}_{\mathrm{R} 2}$ & 0.5 & 1 & 38 & $72: 28$ & 93 & 80 \\
\hline 17 & & & 2 & 20 & $67: 33$ & 77 & 65 \\
\hline 18 & $\mathrm{Aza}^{\mathrm{t}} \mathrm{Bu}-\mathrm{Cu}-\mathrm{PWn}-\mathrm{S}_{\mathrm{G}}$ & 0.66 & 1 & 28 & $74: 26$ & 97 & 87 \\
\hline 19 & & & 2 & 30 & $73: 27$ & 90 & 78 \\
\hline 20 & & & 3 & 25 & $62: 38$ & 40 & 46 \\
\hline 21 & $\mathrm{Aza}^{t} \mathrm{Bu}-\mathrm{Cu}-\mathrm{PWn}-\mathrm{S}_{\mathrm{G}}$ & 0.33 & 1 & 48 & $72: 28$ & 90 & 79 \\
\hline
\end{tabular}




$\begin{array}{lllll}3 & 2 & 60: 40 & 10 & 11\end{array}$

$\begin{array}{llllllll}24 & \mathrm{Aza} & \mathrm{t} \\ \mathrm{Bu} & \mathrm{Cu}-\mathrm{Cu}-\mathrm{P}-\mathrm{A} & 0.5 & 1 & 17 & 74: 26 & 94 & 80\end{array}$

${ }^{a}$ Recovery by method A (see experimental section for details). ${ }^{b}$ Total conversion of ethyl diazoacetate is observed with freshly prepared catalysts. Determined by gas chromatography; $1 R$ cyclopropanes are the major products. ${ }^{\mathrm{c}}$ Reference [43]. Results obtained with methyl diazoacetate, using phenylhydrazine as reductant. ${ }^{\mathrm{d}}$ Reference [37]. 
Table 3. Comparison of the recycling of immobilized Azabox-Cu(II) complexes after cyclopropanation reactions in dichloromethane or styrene as solvent. ${ }^{\text {a }}$

\begin{tabular}{|c|c|c|c|c|c|c|c|c|c|c|}
\hline \multirow[b]{2}{*}{ Catalyst } & \multirow[b]{2}{*}{$\%$ cat } & \multirow[b]{2}{*}{ run } & \multicolumn{4}{|c|}{$\mathrm{CH}_{2} \mathrm{Cl}_{2}$} & \multicolumn{4}{|c|}{ Styrene } \\
\hline & & & $\%$ yield $^{b}$ & trans/cis ${ }^{\mathrm{b}}$ & $\%$ ee trans $^{\mathrm{b}}$ & $\%$ ee $c_{i s}^{\mathrm{b}}$ & $\%$ yield $^{b}$ & trans/cis ${ }^{\mathrm{b}}$ & $\%$ ee trans $^{\mathrm{b}}$ & $\%$ ee $c i s^{\mathrm{b}}$ \\
\hline \multirow[t]{2}{*}{$\mathrm{Aza}{ }^{t} \mathrm{Bu}-\mathrm{Cu}_{0.5}-\mathrm{PWn}-\mathrm{S}_{\mathrm{R}}$} & 0.5 & 1 & 55 & $73: 27$ & 96 & 85 & 60 & $70: 30$ & 96 & 84 \\
\hline & & 3 & 3 & $70: 30$ & 62 & 39 & 10 & $66: 34$ & 20 & 21 \\
\hline \multirow[t]{2}{*}{$\mathrm{Aza}^{\mathrm{t}} \mathrm{Bu}-\mathrm{Cu}-\mathrm{PWn}-\mathrm{S}_{\mathrm{R} 2}$} & 0.5 & 1 & 38 & $72: 28$ & 93 & 80 & 65 & $74: 26$ & 96 & 79 \\
\hline & & 2 & 20 & $67: 33$ & 77 & 65 & 50 & $72: 28$ & 96 & 82 \\
\hline
\end{tabular}

\footnotetext{
${ }^{a}$ Recovery by method A (see experimental section for details). ${ }^{b}$ Total conversion of ethyl diazoacetate is observed with freshly prepared catalysts. Determined by gas chromatography; $1 R$ cyclopropanes are the major products. ${ }^{\mathrm{c}}$ Reference [43]. Results obtained with methyl diazoacetate, using phenylhydrazine as reductant.
} 
Table 4. Effect of the recycling method of immobilized Azabox-Cu(II) complexes. ${ }^{\mathrm{a}}$

\begin{tabular}{|c|c|c|c|c|c|c|c|c|}
\hline Catalyst & $\%$ cat & $\begin{array}{c}\text { Reaction } \\
\text { solvent }\end{array}$ & $\begin{array}{l}\text { Recycling } \\
\text { method }^{\mathrm{b}}\end{array}$ & run & $\%$ yield $^{c}$ & trans $/$ cis $^{\mathrm{c}}$ & $\%$ ee $t_{r a n s}{ }^{\mathrm{c}}$ & $\%$ ee $c i s^{\mathrm{c}}$ \\
\hline \multirow[t]{2}{*}{ Aza ${ }^{i} \operatorname{Pr}-\mathrm{Cu}-\mathrm{PWn}-\mathrm{S}_{\mathrm{R}}$} & 0.22 & $\mathrm{CH}_{2} \mathrm{Cl}_{2}$ & $\mathrm{~B} 1$ & 1 & 47 & $68: 32$ & 70 & 54 \\
\hline & & & & 2 & 21 & $68: 32$ & 49 & 29 \\
\hline \multirow[t]{3}{*}{ Aza ${ }^{i} \operatorname{Pr}-\mathrm{Cu}-\mathrm{PWn}-\mathrm{S}_{\mathrm{R}}$} & 0.2 & Styrene & B2 & 1 & 35 & $65: 35$ & 74 & 50 \\
\hline & & & & 2 & 34 & $66: 34$ & 75 & 51 \\
\hline & & & & 3 & 32 & $65: 35$ & 75 & 52 \\
\hline \multirow[t]{6}{*}{$\mathrm{Aza}^{\mathrm{t}} \mathrm{Bu}-\mathrm{Cu}_{0.2}-\mathrm{PWn}-\mathrm{S}_{\mathrm{R}}$} & 0.7 & Styrene & B2 & 1 & 57 & $62: 38$ & 95 & 83 \\
\hline & & & & 2 & 55 & $70: 30$ & 89 & 80 \\
\hline & & & & 3 & 54 & $62: 38$ & 85 & 72 \\
\hline & & & & 4 & 54 & $62: 38$ & 83 & 66 \\
\hline & & & & 5 & 53 & $61: 39$ & 82 & 66 \\
\hline & & & & 6 & 49 & $62: 38$ & 83 & 65 \\
\hline
\end{tabular}




\begin{tabular}{|c|c|c|c|c|c|c|c|c|}
\hline \multirow[t]{2}{*}{ Aza ${ }^{i} P r-C u-P W n$} & 0.22 & $\mathrm{CH}_{2} \mathrm{Cl}_{2}$ & $\mathrm{C}$ & 1 & 17 & $73: 27$ & 62 & 52 \\
\hline & & & & 2 & 12 & $65: 35$ & 62 & 52 \\
\hline \multirow[t]{2}{*}{ Aza ${ }^{i} \mathrm{Pr}-\mathrm{Cu}-\mathrm{PWn}$} & 0.7 & $\mathrm{CH}_{2} \mathrm{Cl}_{2}$ & $\mathrm{C}$ & 1 & 50 & $66: 34$ & 75 & 55 \\
\hline & & & & 2 & 40 & $66: 34$ & 72 & 56 \\
\hline \multirow[t]{5}{*}{ Aza ${ }^{i} P r-C u-P W n-S_{R}$} & 0.22 & $\mathrm{CH}_{2} \mathrm{Cl}_{2}$ & $\mathrm{C}$ & 1 & 47 & $68: 32$ & 70 & 54 \\
\hline & & & & 2 & 32 & $70: 30$ & 73 & 55 \\
\hline & & & & 3 & 32 & $68: 32$ & 72 & 52 \\
\hline & & & & 4 & 30 & $70: 30$ & 73 & 53 \\
\hline & & & B2 & 5 & 2 & $69: 31$ & 39 & 16 \\
\hline
\end{tabular}

${ }^{\mathrm{a}}$ Total conversion of ethyl diazoacetate is observed in all cases. ${ }^{\mathrm{b}}$ See experimental section for details. ${ }^{\mathrm{c}}$ Determined by gas chromatography; $1 R$ cyclopropanes are the major products. 


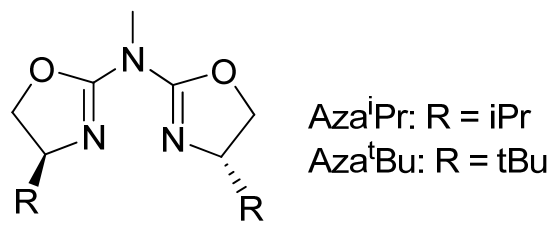

Figure 1. Azabis(oxazoline) ligands with isopropyl and tert-butyl substituents.

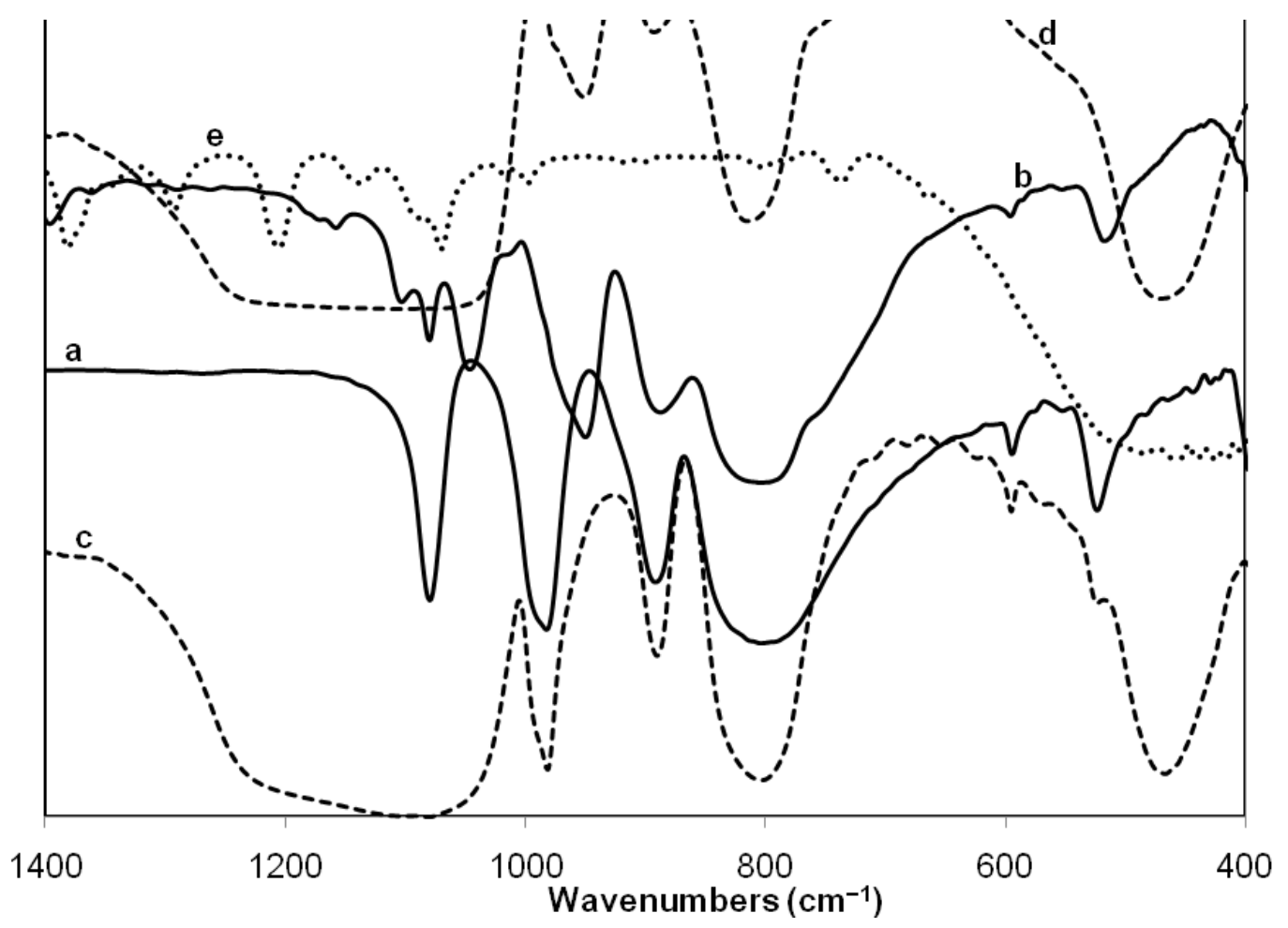

Figure 2. IR spectra of: PW (a), PWn (b), PW-S $\mathrm{S}_{\mathrm{R}}$ (c, dashed line), $\mathrm{PWn}-\mathrm{S}_{\mathrm{R}}$ (d, dashed line), and $\mathrm{Et}_{3} \mathrm{~N}$ (e, dotted line). 


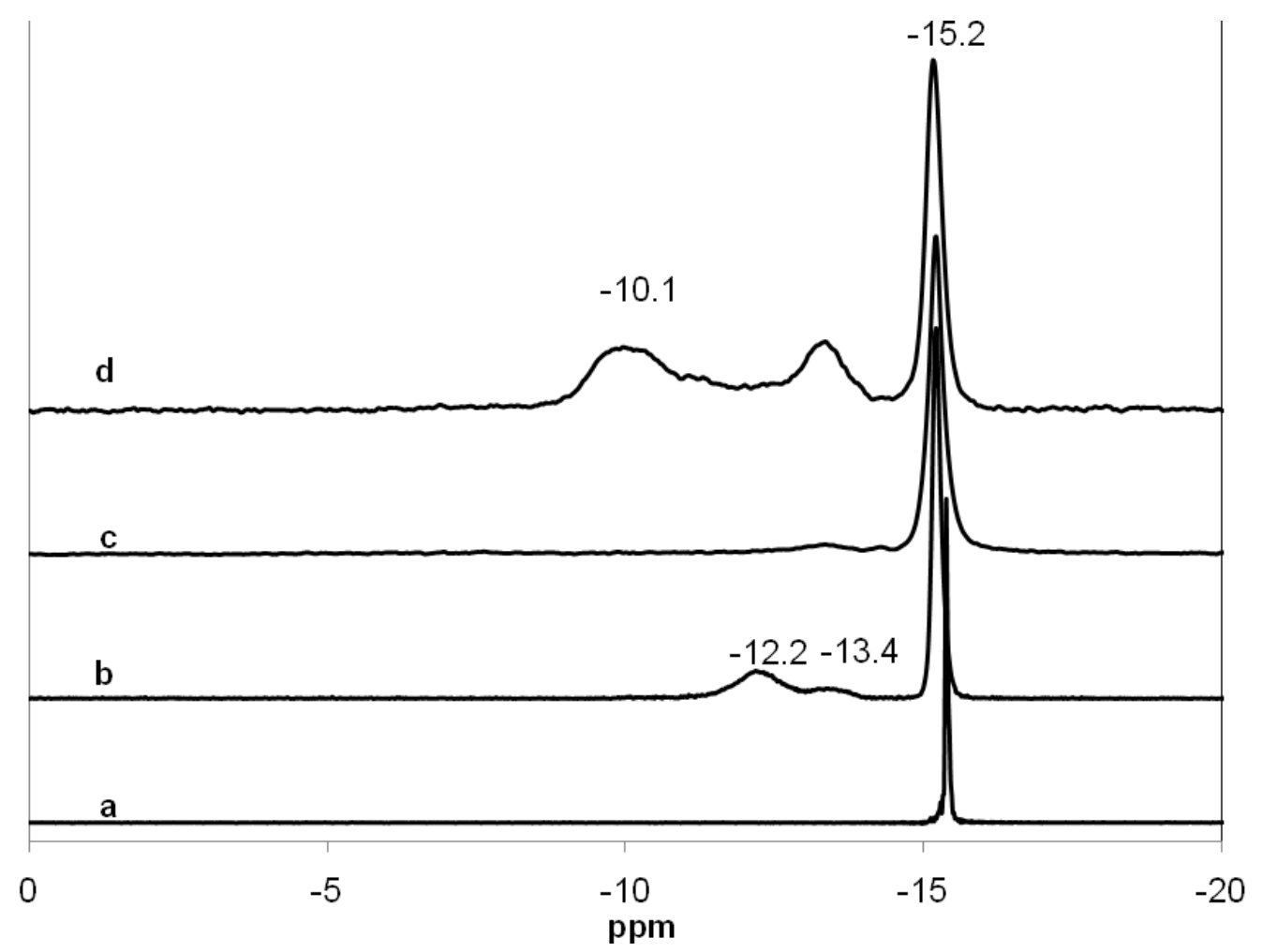

Figure 3. ${ }^{31} \mathrm{P}-\mathrm{CP}-\mathrm{MAS}-\mathrm{NMR}$ spectra of: $\mathrm{PW}(\mathrm{a}), \mathrm{PWn}(\mathrm{b}), \mathrm{PW}-\mathrm{S}_{\mathrm{R}}(\mathrm{c}), \mathrm{PWn}-\mathrm{S}_{\mathrm{R}}(\mathrm{d})$.

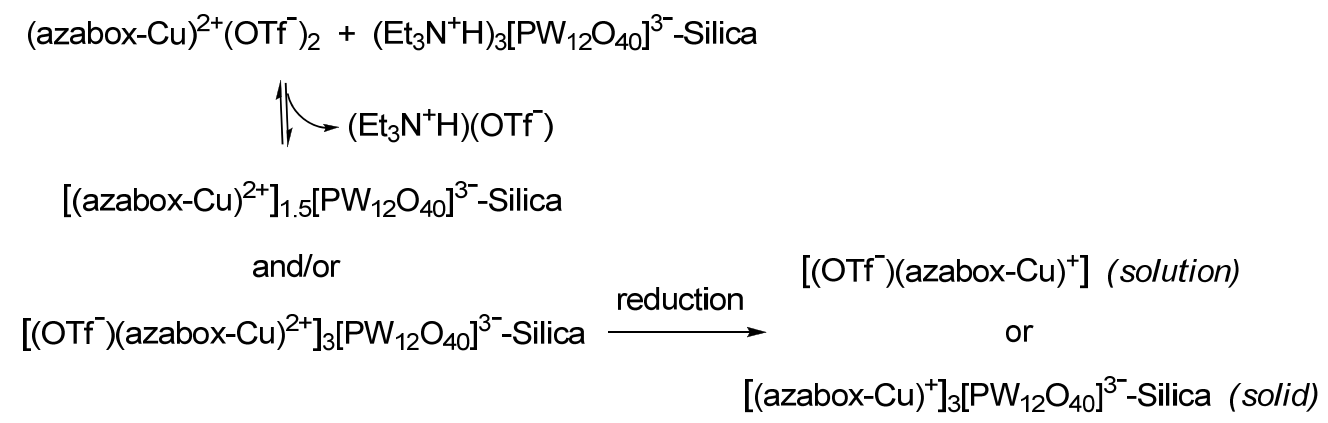

Figure 4. Mono- and di-exchanged species and the possible effect of $\mathrm{Cu}(\mathrm{II})-\mathrm{Cu}(\mathrm{I})$ reduction. 


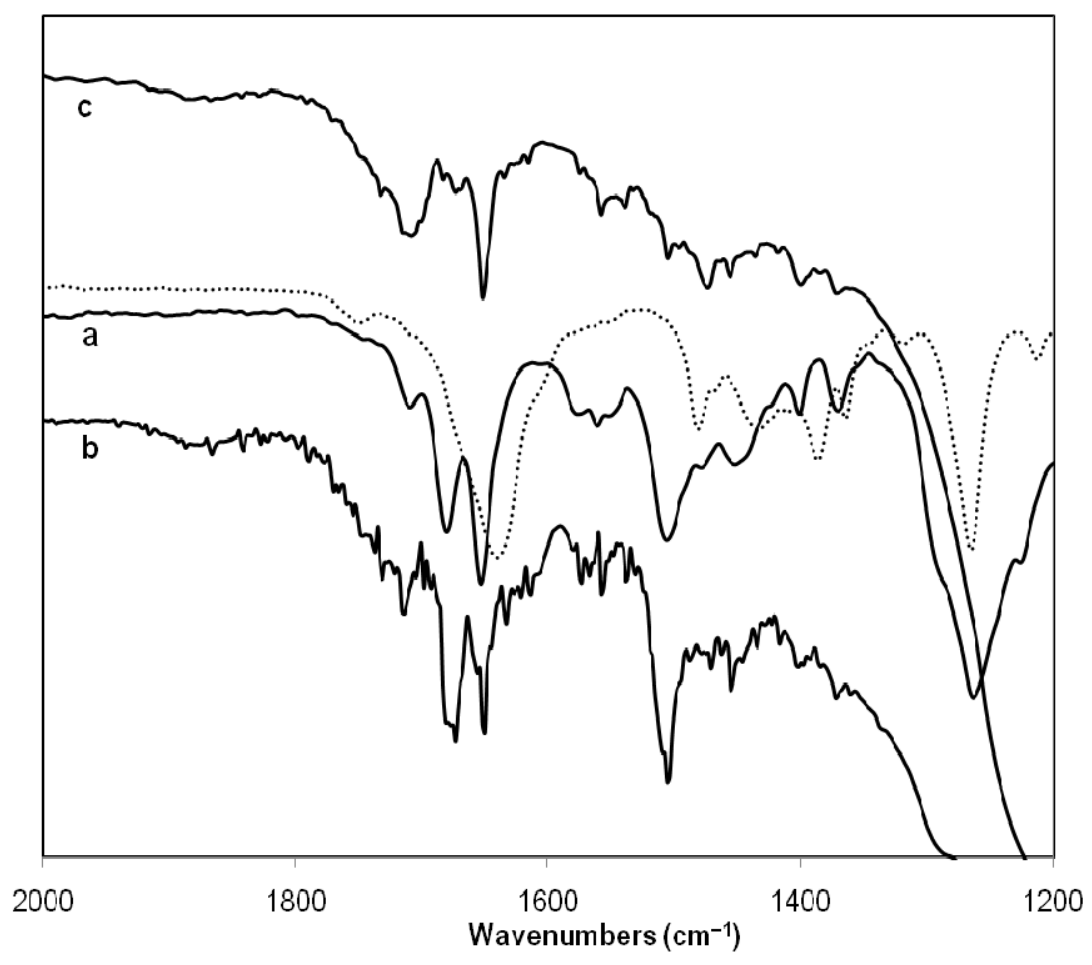

Figure 5. IR spectra of $\mathrm{Aza}{ }^{t} \mathrm{Bu}-\mathrm{Cu}(\mathrm{OTf})_{2}$ (a) and two different samples of $\mathrm{Aza}{ }^{\mathrm{t}} \mathrm{Bu}-\mathrm{Cu}-$ $\mathrm{PWn}-\mathrm{S}_{\mathrm{R}}(\mathrm{b}$ and $\mathrm{c})$ in comparison with the spectrum of free $\mathrm{Aza}{ }^{\mathrm{t}} \mathrm{Bu}$ (dotted line). 


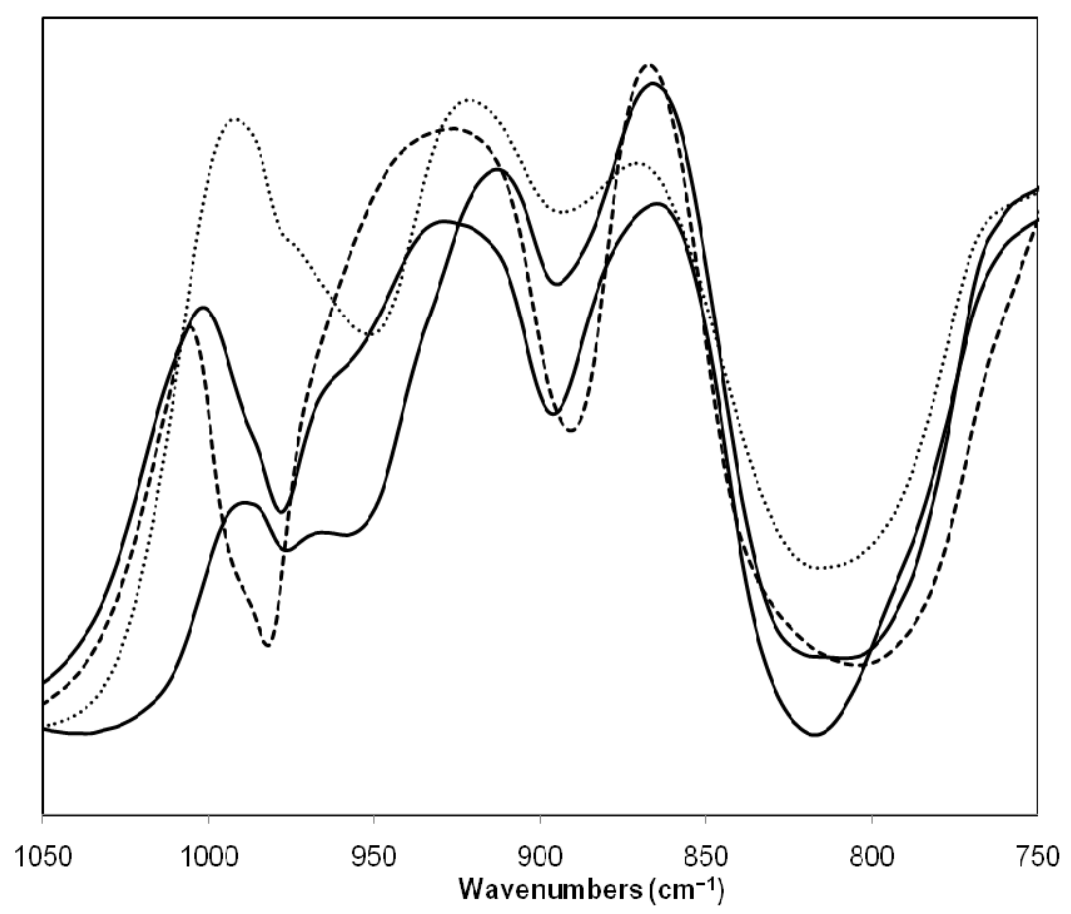

Figure 6. IR spectra of $\mathrm{PW}-\mathrm{S}_{\mathrm{R}}$ (dashed line), $\mathrm{PWn}-\mathrm{S}_{\mathrm{R}}$ (dotted line) and two different samples of $\mathrm{Aza}{ }^{\mathrm{t}} \mathrm{Bu}-\mathrm{Cu}-\mathrm{PWn}-\mathrm{S}_{\mathrm{R}}$ (solid lines).

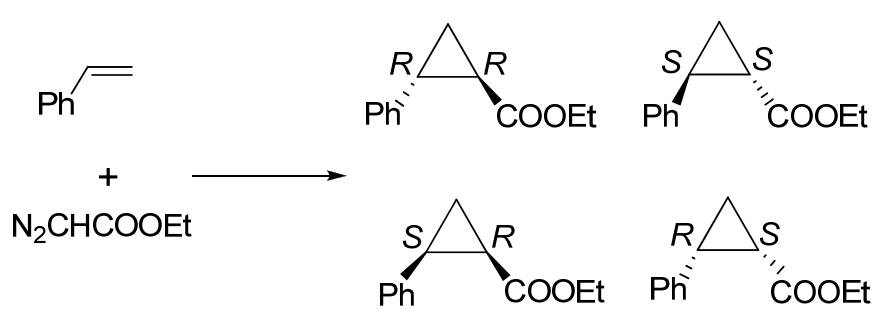

Figure 7. Cyclopropanation reaction between styrene and ethyl diazoacetate. 